\title{
Elementos caracterizadores de ingresso e evasão em um curso de licenciatura em Química
}

\section{Viviane Arrigo}

viviane arrigo@hotmail.com

orcid.org/0000-0002-0683-8387

Universidade Estadual de Londrina (UEL), Londrina, Paraná, Brasil

Miriam Cristina Covre de Souza miriam.covre@gmail.com

orcid.org/0000-0001-6473-196X

Universidade Estadual de Londrina (UEL), Londrina, Paraná, Brasil

Fabiele Cristiane Dias Broietti

fabieledias@uel.br
orcid.org/0000-0002-0638-3036

Universidade Estadual de Londrina (UEL), Londrina, Paraná, Brasil

\section{RESUMO}

O objetivo deste artigo residiu em analisar a trajetória ${ }^{1}$ acadêmica dos estudantes de um curso de licenciatura em Química ingressantes nos anos de 2011 a 2014, desde o seu ingresso até o final de 2016. Os dados analisados consistem em relatórios fornecidos pela Pró-reitoria de Graduação de uma universidade pública do estado do Paraná, referentes ao ingresso dos estudantes de 2011 a 2014 e a trajetória de cada um até o final de 2016. Para analisar e interpretar os dados foi utilizada a Análise de Conteúdo. As discussões aqui apresentadas consistem nos primeiros resultados de um projeto de pesquisa ainda em execução. Os dados apontam que o ingresso dos estudantes de 2012 a 2014 foi predominantemente via ENEM, visto que em 2011 ainda não existia a possibilidade de ingressar por este processo; o total de evadidos por ano de ingresso equivale a mais da metade da turma; a categoria que engloba o maior número de estudantes evadidos está relacionada ao Abandono (39\%), seguida das categorias Cancelamento de Matrícula (33\%) e Desistência (22\%). É evidente que a diplomação ou evasão dos estudantes não pode ser interpretada apenas como valores numéricos, é fundamental ter-se clareza dos fatores e motivos que os levam a evadir e a forma como a organização curricular do curso influencia para a desistência, abandono, trancamento de matrícula, enfim, a interrupção dos estudos, objetivo futuro da nossa investigação.

PALAVRAS-CHAVE: Evasão. Ensino Superior. Licenciatura. Química. Formação de Professores. 


\section{INTRODUÇÃO}

Nos últimos anos vem ocorrendo um crescimento no número de estudantes matriculados em cursos de Ensino Superior. Essa expansão pode ser explicada por duas razões: aumento no número de instituições que ofertam cursos de Ensino Superior em distintos níveis administrativos, e incentivos do governo federal em programas que estimulam o acesso de estudantes de baixa renda a universidades, como o Programa Universidade para Todos - PROUNI² - (INEP, 2015).

No entanto, simultaneamente a esse aumento encontramos problemas relacionados ao fenômeno da evasão, ainda mais acentuado nos cursos voltados para a área de formação de professores. Para Mezomo (1999, p. 117) esse fenômeno "implica em prejuízos, para si, para a instituição e para a sociedade".

De acordo com Arruda e Passos (2015) a evasão pode ser compreendida por meio da representação exposta na Figura 1.

Figura 1 - Representação da evasão do estudante E

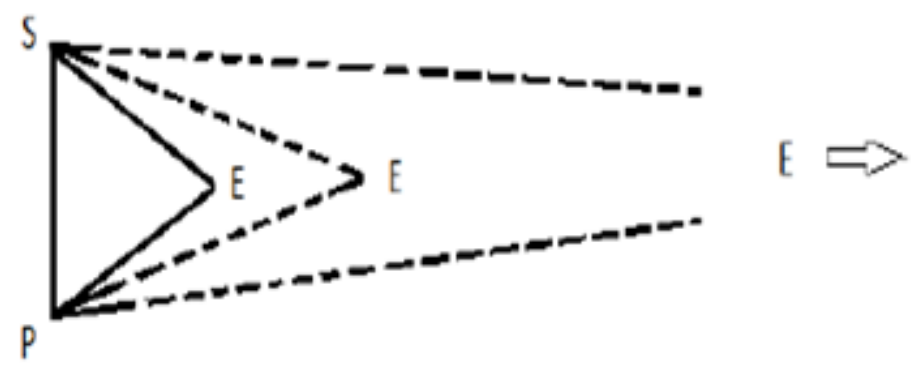

Fonte: Arruda e Passos (2015, p. 6).

A Figura 1, inspirada no sistema didático de Chevallard (2005), representa uma estrutura constituída por três "lugares" P (o professor), E (o estudante) e S (o saber) e suas inter-relações. Para Arruda e Passos (2015) se o ponto E - o estudante - vai se afastando dos outros dois, a representação obtida pode simular a situação de evasão. Dessa forma, a Figura 1 indica que a evasão pode ter ocorrido em decorrência de problemas na relação de $\mathrm{E}$ com $\mathrm{P}$ (relação do estudante com o professor/relação de ensino - segmento EP); na relação de E com S (relação do estudante com o conteúdo/relação de aprendizagem - segmento ES); na relação com ambos os segmentos; ou ainda relacionada a condições externas (necessidade de trabalho, doenças, falta de transporte, distância, problemas socioeconômicos etc.).

No entanto, o tema evasão no Ensino Superior ainda é pouco explorado no cenário nacional, tendo intensificado as pesquisas a partir de 1995 com a criação da Comissão Especial de Estudos sobre Evasão, oficialmente constituída através das portarias da Secretaria de Educação Superior, de 13 e 17 de março de 1995, publicadas no Diário Oficial da União, respectivamente em 18 e 21 de março, cujo objetivo era desenvolver um estudo acerca do desempenho das Instituições Federais de Ensino Superior (VELOSO; ALMEIDA, 2002). Segundo Santos (1999), as pesquisas envolvendo a temática evasão ainda não são suficientes para explicar em detalhes os motivos das desistências dos discentes nos cursos. Por isso, o referido tema tem gerado preocupação para as universidades, uma vez que traz perdas para o campo social e econômico (SILVA FILHO et al., 2007; CUNHA; TUNES; SILVA, 2001; PATTO, 1996). 
Diante de tal situação, e frente à escassa quantidade de estudos sistemáticos sobre o tema, propusemos um projeto de pesquisa em que levantamos os seguintes questionamentos: por que formamos poucos estudantes nos cursos de licenciatura em Química? Quais os motivos das desistências? Por que outros estudantes persistem? Elencamos como etapas da investigação buscar uma visão mais aprofundada acerca dos motivos e interesses que os estudantes apresentam acerca da permanência no curso e eventuais fatores que afetam favoravelmente para a sua desistência.

Vale ressaltar que, o presente artigo traz os primeiros resultados desse projeto ainda em execução, que tem por objetivo identificar os motivos e interesses que estudantes de um curso de licenciatura em Química de uma universidade pública do estado do Paraná apresentam acerca da permanência no curso, bem como eventuais fatores que contribuem para a sua desistência. Neste trabalho, em especial, trazemos algumas reflexões oriundas das análises de relatórios disponibilizados pela PROGRAD - Pró-Reitoria de Graduação, da instituição investigada, no qual constam dados dos estudantes ingressantes de um curso de licenciatura em Química nos anos de 2011 a 2014, bem como sua trajetória acadêmica ao longo do curso até o final de 2016.

\section{ASPECTOS GERAIS ACERCA DO FENÔMENO DA EVASÃO}

Como citado anteriormente, a evasão no Ensino Superior gera preocupação para as instituições de Ensino Superior (IES) e traz perdas para o campo social, acadêmico e econômico (SILVA FILHO et al., 2007; PATTO, 1996; CUNHA; TUNES; SILVA, 2001). Entretanto, esse problema parece ter recebido pouca atenção nas IES, pois segundo estudo realizado por Bordas (1996) a administração da instituição vê com surpresa os percentuais de evasão apresentados na pesquisa.

Para realizar ações de combate à evasão escolar, Sganzerla (2001) destaca que as instituições devem realizar uma análise da atual situação, e levar em consideração suas características peculiares, como comunidade onde está inserida, estrutura física e de pessoal.

Segundo Bordas (1996) o Brasil apresenta alto índice de evasão nos cursos superiores, em torno de $50 \%$, e os motivos destacados pelo autor estão relacionados à falta de atenção e o despreparo das IES. Nessa mesma pesquisa o autor ainda ressalta que os gestores das universidades apontaram causas que não têm relação com o que realmente os alunos que desistiram expressaram.

Na pesquisa realizada por Gatti (2014) a respeito da relação complexa entre pesquisa e políticas educacionais, a autora faz uma síntese do estado do conhecimento sobre formação inicial de professores nos cursos de graduação, por meio da qual ela constata que os estudantes que procuram os cursos de licenciatura apresentam características socioeducacionais e culturais que merecem ser consideradas para sua melhor formação e permanência no curso. As pesquisas examinadas pela autora indicam que os estudantes que frequentam as licenciaturas são um pouco mais velhos quando comparados aos demais cursos de graduação, a maioria deles provêm de escolas públicas - escolas que apresentam problemas na formação oferecida, se considerarmos os indicadores existentes e por essa razão, 
[...] é importante ter bons planejamentos curriculares e didáticos, com a criação de estímulos culturais e aproveitamento da motivação que esses segmentos portam. Para tanto, porém, é necessário não só um envolvimento pedagógico adequado com os licenciandos como também um projeto institucional para o acolhimento e formação desses alunos (GATTI, 2014, p. 48).

Já a pesquisa realizada por Silva Filho e colaboradores (2007) aponta que a média anual de evasão entre 2000 a 2005, para o conjunto formado por todas as IES (públicas e privadas) do Brasil, foi de $22 \%$, sendo que a evasão média nas IES públicas neste mesmo período oscilou em torno de $12 \%$. Apesar destes resultados serem inferiores aos apontados por Bordas (1996), os autores destacam que esses valores tendem a aumentar com o passar dos anos.

Para Paredes (1994) o fenômeno da evasão escolar no Ensino Superior carrega muita complexidade, o que faz tornar muito difícil de identificar os fatores que realmente provocam a desistência de alunos nos cursos da graduação.

Silva Filho et al. (2007) destacam que geralmente as instituições públicas e privadas consideram que o principal motivo da evasão dos estudantes é a falta de recursos financeiros para estes prosseguirem nos estudos. E este também é a principal razão declarada pelo estudante quanto lhe é perguntado a principal razão da evasão. No entanto, segundo os autores,

[...] pesquisas indicam que essa resposta é uma simplificação, uma vez que as questões de ordem acadêmica, as expectativas do aluno em relação à sua formação e a própria integração do estudante com a instituição constituem, na maioria das vezes, os principais fatores que acabam por desestimular o estudante a priorizar o investimento de tempo ou financeiro, para conclusão do curso. (SILVA FILHO et al., 2007, p. 643).

Contudo, de acordo com Bordas (1996) os motivos da evasão podem ser divididos em três grupos, assim identificados: causas internas, externas e aquelas relacionadas ao estudante.

As causas internas estão ligadas aos recursos humanos, a infraestrutura da instituição e os aspectos pedagógicos do curso. Para Anderson (1987), existe uma relação de fatores internos que podem levar o discente a concluir ou desistir do curso, são eles: aptidão mínima de conhecimento e estudo que tornam possível a entrada e realização na faculdade; estímulo, empenho e insistência para as tarefas acadêmicas; possíveis ganhos em graduar-se em um curso do Ensino Superior que proporcionará oportunidades pessoais; necessidade profissional para elevação em alguma carreira que exija o curso superior; princípios que distinguem a importância do Ensino Superior; utilização como referência de outras pessoas graduadas como estímulo; falta de recursos materiais por parte da instituição; problemas com a moradia estudantil ou transporte para a instituição; divergência no trabalho, principalmente relacionado ao horário; demandas sociais; desaprovação da família ou amigos que não valorizam a formação superior; discriminação racial; obrigações com a família.

As causas externas estão relacionadas ao aspecto social, político e econômico. Segundo Anderson (1987), os fatores externos que podem levar ao sucesso ou desistência do estudante são: família, principalmente os pais que reconhecem a importância do Ensino Superior; grupos socioeconômicos frequentados pelo estudante que têm os mesmos objetivos e reconhecem a importância do Ensino 
Superior; princípios culturais que ressaltam o conhecimento, oportunidade intelectual de realizar a educação superior; oportunidades oferecidas pelo curso de graduação - participação de projetos com ajuda financeira, bolsas de estudo, e chance para o desenvolvimento intelectual e pessoal a partir do curso de graduação; oportunidade de conhecer e ampliar o grupo de relacionamentos. Gaioso (2005) destaca como fatores econômicos que podem estar atrelados à evasão, problemas financeiros como, a falta de emprego, ou a escolha por parte do estudante em trabalhar ao invés de estudar.

O terceiro grupo de fatores da evasão é aquele relacionado aos estudantes, referentes à vocação do curso ou outros problemas de ordem pessoal. Anderson (1987) afirma ainda que algumas das forças que agem contra a permanência do estudante e a realização do curso são: processos institucionais como matrículas, registro, etc.; escolha dos cursos apropriados; compreensão de textos e realização de provas; atividades que envolvem pesquisas, elaboração de textos e apresentação de trabalhos, dentro de padrões estabelecidos pela instituição ou professores.

Para Arruda et al. (2006) outro motivo significativo para a evasão escolar é a falta de informações sobre o curso e também a profissão escolhida. Muitas vezes o aluno opta em fazer determinado curso, mas quando começa a estudar verifica que não condiz com a realidade, ou com aquilo que imaginava que a profissão the ofereceria.

\section{A FORMAÇÃO INICIAL DE PROFESSORES - AS LICENCIATURAS}

Segundo dados disponíveis na Sinopse Estatística da Educação Superior do ano de 2015, disponíveis no site do INEP, o número de IES no Brasil (universidades, centros universitários, faculdades, institutos federais e CEFET) constitui um total de 2.364 IES. Dentre os 33.501 cursos de graduação presenciais e à distância ofertados por estas instituições, 7.629 se referem às licenciaturas, das quais 356 correspondem à formação de professores de Química. Nos últimos anos houve uma crescente demanda por pessoas interessadas em realizar curso superior. Em 2014 o número de estudantes matriculados ultrapassou 7,3 milhões enquanto que no ano de 2005 esse número não chegava a 2 milhões de estudantes (INEP, 2015).

No entanto, apesar do alto índice de matrículas em cursos de graduação presenciais e à distância, ainda é perceptível a baixa procura por cursos de licenciatura, em especial os das áreas específicas de Química e Física. No ano de 2015, das 8.027.297 matrículas efetivadas em cursos superiores 1.471.930 destinaram-se a cursos de licenciatura e, destas, 35.170 referem-se aos cursos de formação de professores de Química (INEP, 2015).

Ainda hoje, em muitas universidades, a prática de formação inicial de professores tem sido realizada de forma restrita e não problematizada, uma vez que, é diferente saber os conteúdos de Química em um contexto de Química e sabê-los em um contexto de mediação pedagógica (MALDANER, 2013). Por isso, as Diretrizes Curriculares Nacionais (DCN) para a Formação Inicial e Continuada dos Profissionais do Magistério da Educação Básica (BRASIL, 2015) traz à tona a necessidade de se estabelecer uma correlação entre teoria e prática, um movimento contínuo entre o saber e o fazer, na busca de resolução de situações 
próprias do ambiente escolar, a partir do cruzamento dos diferentes componentes curriculares: formação específica e formação pedagógica ao longo do curso.

Nessa perspectiva, observa-se uma crescente preocupação por parte dos pesquisadores da área em conhecer como se dá o processo de aprender a ensinar, considerando-o não mais nos moldes de um currículo normativo o que sugere uma ordem pré-definida, apresentando primeiramente a ciência, seguida de suas aplicações e, por fim, um estágio que supõe a aplicação pelos estudantes dos conhecimentos técnico-profissionais.

Em torno destas demandas, os cursos de formação de professores atualmente estão passando por reformulações em seus currículos, a fim de atender as solicitações do parecer CNE/CP no 2/2015. É destacada a necessidade em reconhecer as deficiências científicas e a pobreza conceitual dos programas atuais de formação de professores e proposto um aumento de carga horária de $\mathbf{2 8 0 0}$ horas para 3200 horas de efetivo trabalho acadêmico. O novo currículo deve apresentar 2200 horas distribuídas nos núcleos I - estudos de formação geral - e II - aprofundamento e diversificação de estudos das áreas de atuação profissional - e, 200 horas de atividades teórico-práticas de aprofundamento em áreas específicas de interesse dos estudantes, como definido no núcleo III - estudos integradores para enriquecimento curricular -, por meio da iniciação científica, iniciação à docência, extensão e/ou monitoria, conforme o projeto de curso (BRASIL, 2015). As DCN ainda evidenciam que deverá ser garantida ao longo do processo de formação do licenciando, "efetiva e concomitante relação entre teoria e prática, ambas fornecendo elementos básicos para o desenvolvimento dos conhecimentos e habilidades necessários à docência" (BRASIL, 2015, p. 30-31).

Neste trabalho, trazemos as primeiras impressões provenientes da análise dos dados referentes às turmas ingressantes nos anos de 2011 a 2014, de um curso de licenciatura em Química. Portanto, nosso objetivo residiu na análise da trajetória acadêmica destes estudantes desde o seu ingresso até o final de 2016.

\section{METODOLOGIA}

Inicialmente, solicitamos à PROGRAD, Pró-reitoria de Graduação da universidade em questão, relatórios referentes às turmas ingressantes de 2011 a 2014 do curso de licenciatura em Química, contendo o nome e o número de matrícula dos estudantes, formas de ingresso (cota universal - vestibular -, cota de escola pública, cota de negro ou pardo oriundo de escola pública, ou por intermédio do ENEM - Exame Nacional do Ensino Médio) e a trajetória particular de cada estudante desde o seu ingresso no curso até final de 2016 (cursando, formado, formado ativo - colou grau em licenciatura e está cursando outra graduação na instituição - ou evadido).

Diante dos relatórios, para a análise dos dados, optamos pelos procedimentos e definições da Análise de Conteúdo (AC) apresentadas por Bardin (2011). Segundo a autora, a análise de conteúdo pode ser organizada em três etapas, a pré-análise, a exploração do material e o tratamento dos resultados obtidos e interpretação.

A primeira etapa consiste na organização e sistematização das ideias, em que ocorre a escolha dos documentos para análise, a retomada das hipóteses e dos objetivos iniciais da pesquisa. Neste estudo, como objetivávamos neste primeiro 
momento, analisaremos dados de relatórios da PROGRAD, em que constam informações sobre os ingressantes de um curso de licenciatura em Química (2011 a 2014) bem como sua trajetória ao longo do curso, solicitamos estes relatórios e de posse do material, realizamos diversas leituras a fim de organizarmos as informações ali contidas.

Durante a exploração do material, desenvolve-se a codificação e, em seguida, a categorização; é nessa etapa que o pesquisador procura identificar e assumir se suas categorias serão definidas a priori ou a posteriori. Nesta pesquisa, após examinar os relatórios e frente aos dados nele expressos assumimos categorias a priori, de acordo com os dados fornecidos pela PROGRAD.

Segundo os dados fornecidos pela PROGRAD, para o curso de licenciatura em Química, referente aos ingressantes no período de 2011 a 2014, as justificativas para evasão foram: cancelamento de matrícula, desistente, abandono (Art. $43^{3}$ ), trancamento de matrícula e transferência interna. Estas alegações foram consideradas nossas categorias a priori, as quais estão descritas no Quadro 1.

Quadro 1 - Categorias de evasão e suas descrições

\begin{tabular}{c|c}
\hline $\begin{array}{c}\text { Categorias de } \\
\text { Evasão }\end{array}$ & Descrição \\
\hline $\begin{array}{c}\text { Cancelamento de } \\
\text { matrícula }\end{array}$ & $\begin{array}{c}\text { O cancelamento de matrícula ocorre quando o estudante a solicita } \\
\text { por escrito. }\end{array}$ \\
\hline Desistente & $\begin{array}{c}\text { É considerado desistente o estudante que não renova a matrícula } \\
\text { dentro dos prazos previstos, salvo motivo justificado e comprovado. }\end{array}$ \\
\hline Abandono (Art. 43) & $\begin{array}{c}\text { É considerado abandono (Art. 43), quando o estudante é reprovado } \\
\text { em todas as atividades acadêmicas por nota e frequência durante 1 } \\
\text { (um) ano letivo ou por 2 (dois) semestres consecutivos, desde que } \\
\text { nano esteja amparado legalmente. }\end{array}$ \\
\hline matrícula & $\begin{array}{c}\text { O trancamento de matrícula é requerido pelo estudante junto à } \\
\text { PROGRAD para o ano letivo/semestre letivo em curso; não pode } \\
\text { ocorrer na primeira série do regime acadêmico anual ou no } \\
\text { primeiro semestre do regime acadêmico semestral, salvo por } \\
\text { problemas de saúde. }\end{array}$ \\
\hline $\begin{array}{c}\text { Transferência } \\
\text { interna }\end{array}$ & $\begin{array}{c}\text { A transferência interna ocorre quando o estudante transfere de } \\
\text { turno (dentro do próprio curso) ou permuta de um curso para outro } \\
\text { dentro da própria instituição de ensino. }\end{array}$ \\
\hline
\end{tabular}

Fonte: Autoria própria (2017).

Por fim, no tratamento dos resultados obtidos e interpretação se faz a categorização, que tem por finalidade agrupar os dados mediante critérios definidos (BARDIN, 2011). As categorias acima apresentadas possibilitaram alocar os estudantes de acordo com a evolução das turmas ingressantes nos anos de 2011 a 2014. Estes dados serão explanados e discutidos na seção seguinte.

\section{RESULTADOS E DISCUSSÃO}

Para uma melhor compreensão e análise da trajetória dos estudantes ao longo do curso de licenciatura em Química e dos dados de evasão, fornecidos pela 
PROGRAD, inicialmente apresentamos no Quadro 2 a quantidade de ingressantes e o processo de ingresso dos estudantes no curso em questão referente aos anos de 2011 a 2014.

Quadro 2 - Total de ingressantes no curso de licenciatura em Química nos anos de 2011 a 2014 e o processo de ingresso

\begin{tabular}{c|c|c|c|c}
\hline \multirow{2}{*}{ Processo de ingresso } & \multicolumn{4}{c}{ Ano } \\
\cline { 2 - 5 } & 2011 & 2012 & 2013 & 2014 \\
\hline Vestibular & 19 & 8 & 4 & 7 \\
\hline Cota de Escola Pública & 21 & 2 & 2 & - \\
\hline Cota de negro ou pardo de escola pública & 4 & 1 & 1 & - \\
\hline ENEM & - & 19 & 23 & 28 \\
\hline Transferência interna & - & - & 1 & 2 \\
\hline Total & 44 & 30 & 31 & 37 \\
\hline
\end{tabular}

Fonte: Autoria própria (2017).

O curso de licenciatura em Química da universidade pesquisada disponibiliza um total de 40 vagas por turma, sendo ofertado no período noturno. No Quadro 2, observamos que apenas em 2011 o total de vagas foi preenchido, neste ano nota-se que houve maior número de ingressantes do que o número de vagas; as 4 vagas excedentes são referentes a cota de negros ou pardos que não estavam incluídas nas 40 vagas iniciais.

No ano de 2012 houve o menor número de ingressantes, apenas 30, restando $25 \%$ das vagas.

A presença de vagas ociosas, nos anos de 2012, 2013 e 2014, indica a baixa procura pelo curso, mesmo sendo viabilizadas várias formas de ingresso. Sá e Santos (2011) analisaram dados do MEC de 2007 e identificaram uma pequena procura pelos cursos de licenciatura em Química. Em 2015, oito anos após a pesquisa de Sá e Santos (2011), o resultado ainda é semelhante. De acordo com as Sinopses Estatísticas da Educação Superior - Graduação, o número de matrículas em cursos de licenciatura presenciais e à distância foi de 1.471.930, e destas, apenas 35.170 se referiram a cursos de formação de professores de Química (INEP, 2015). Diante dos valores apresentados, é perceptível a limitada procura pelos cursos de licenciatura, em especial os da área específica de Química, quando comparados com a Matemática ou a Biologia, que apresentaram em 2015 um número de ingressantes de 82.737 e 83.314 , respectivamente (INEP, 2015).

Alguns autores (RAMOS, 2016; SÁ; SANTOS, 2011; FARIAS; FRANCISCO JUNIOR; FERREIRA, 2010) acreditam que um dos fatores determinantes pode estar associado ao pensamento de senso comum de que esta é uma área difícil, o que acaba muitas vezes sendo reforçado pelos professores da Educação Básica, o que acaba por colaborar na baixa procura dos estudantes por estes cursos.

Ainda analisando o Quadro 2, em 2011 não houve ingresso pela nota do ENEM, isto só aconteceu a partir de 2012. Esse dado é interessante uma vez que em 2011 a maior entrada foi por cota de escola pública, seguida pelo vestibular. A partir de 2012, percebe-se uma diminuição drástica de ingresso via cota de escola pública, sendo esta substituída pelo ENEM. Percebe-se também a diminuição de 
ingressantes pelo vestibular, ou seja, nos anos de 2012 a 2014 a principal via de ingresso no curso de licenciatura em Química se deu pela nota do ENEM, ficando o vestibular em segundo lugar.

O ingresso em um curso universitário pelo ENEM, nos deixa dúvidas em relação à opção pelo curso. Segundo Fernandes et al. (2016, p. 02) "muitos alunos do Ensino Médio acabam optando pela licenciatura porque não obtiveram pontuação suficiente para ingressar no curso desejado", visto que os cursos de licenciatura possuem as menores concorrências por vagas nos vestibulares. Assim, esses estudantes não possuem aptidão para exercer a profissão e esse fato pode explicar os dados de evasão que serão discutidos a seguir.

Quadro 3 - Quantidade de estudantes evadidos por ano de curso

\begin{tabular}{|c|c|c|c|c|c|c|c|}
\hline \multirow{2}{*}{$\begin{array}{l}\text { Ano de } \\
\text { Ingresso }\end{array}$} & \multicolumn{6}{|c|}{ Evadidos por ano } & \multirow{2}{*}{$\begin{array}{l}\text { Evadidos } \\
\text { / ano de } \\
\text { ingresso }\end{array}$} \\
\hline & 2011 & 2012 & 2013 & 2014 & 2015 & 2016 & \\
\hline 2011 & 1 & 6 & 4 & 4 & 4 & 3 & 22 \\
\hline 2012 & - & 2 & 8 & 2 & 5 & 3 & 20 \\
\hline 2013 & - & - & 2 & 12 & 2 & 2 & 18 \\
\hline 2014 & - & - & - & 6 & 6 & 7 & 19 \\
\hline Total & 1 & 8 & 14 & 24 & 17 & 15 & 79 \\
\hline
\end{tabular}

Fonte: Autoria própria (2017).

Ao analisarmos a trajetória dos estudantes ao longo do curso com base nos dados fornecidos pela PROGRAD, constatamos para o ano de 2011 que dos 44 ingressantes, apenas $5(11,36 \%)$ estudantes concluíram o curso no tempo previsto (em 2014 - curso com duração de quatro anos), 6 deles concluíram no ano seguinte, em 2015 e 11 estudantes ainda estão matriculados. Os outros 22 são os evadidos. Para o ano de 2012, dos 30 ingressantes, apenas $8(26,66 \%)$ concluíram o curso no tempo previsto, em 2015 e 2 estudantes ainda estão matriculados em outras séries do curso. Outros 20 estudantes estão evadidos. Para o ano de 2013, dos 31 ingressantes, apenas 7 (22,5\%) estão em fase de conclusão do curso, enquanto 6 ainda estão matriculados em outras séries do curso. Os outros 18 estão evadidos. Para o ano de 2014, dos 37 ingressantes, apenas $6(16,2 \%)$ estudantes estão matriculados na série prevista (3a série), enquanto 12 deles estão matriculados em outras séries do curso. Os outros 19 estão evadidos.

Diante destes resultados buscamos nas Sinopses Estatísticas da Educação Superior - Graduação, analisar a projeção da permanência, conclusão e evasão dos estudantes matriculados em cursos de formação de professores de Química presenciais e a distância do Brasil, entre os anos de 2011 a 2014. Os dados evidenciaram que a média de estudantes que concluíram o curso nestes anos equivale a 10,6 \% do total de matrículas, visto que em 2011, dos 34.920 matriculados, 4.075 concluíram o curso (INEP, 2011); em 2012, dos 35.310 matriculados, 3.615 o concluíram (INEP, 2012); em 2013, dos 35.229 matriculados, 3.436 o concluíram (INEP, 2013); e, em 2014, dos 35.892 matriculados, 3.893 o concluíram (INEP, 2014). 
Para maior clareza na identificação dos valores contidos nos documentos do INEP ${ }^{4}$ referentes aos anos de 2011 a 2014, construímos o Quadro 4, que ilustra, a partir do número total de estudantes matriculados, o número de evadidos via trancamento de matrícula, desvinculação de matrícula ou transferência para outro curso da mesma IES, bem como os concluintes.

Quadro 4 - Dados dos cursos de Formação de professores de Química presenciais e a distância do Brasil

\begin{tabular}{c|c|c|c|c}
\hline Ano de Ingresso & 2011 & 2012 & 2013 & 2014 \\
\hline Matriculados & 34.920 & 35.310 & 35.229 & 35.892 \\
\hline Matrículas Trancadas & 4.010 & 4.274 & 4.394 & 4.421 \\
\hline $\begin{array}{c}\text { Matrículas desvinculadas } \\
\begin{array}{c}\text { Transferência para outro curso } \\
\text { da mesma IES }\end{array}\end{array}$ & 7.607 & 8.427 & 8.866 & 8.376 \\
\hline Concluintes & 4.075 & 3.615 & 3.436 & 316 \\
\hline
\end{tabular}

Fonte: Adaptado de INEP $(2011,2012,2013,2014)$.

Verificamos, portanto, que o número de estudantes diplomados em relação ao número total de matriculados é extremamente baixo, assim como os indicativos identificados para a universidade analisada nesta investigação. Vale ainda ressaltar que no ano de 2011, o percentual de estudantes que concluíram o curso está relativamente próximo a média indicativa encontrada nos dados do INEP. Já para os anos de 2012, 2013 e 2014, os percentuais apresentam-se um pouco mais elevados que a média, o que pode ser justificado pelo fato do número de ingressantes ser menor que em 2011.

No que diz respeito à evasão dos estudantes, as informações contidas no Quadro 3 indicam que independente do ano de ingresso, o ano de 2014 apresentou um alto índice de evasão, o que interpretamos ter ocorrido em função da greve dos professores que durou em torno de 46 dias. Contudo, independente desse fato, em outros anos como em 2015 e 2016, também observamos a existência de estudantes evadidos em todas as turmas ingressantes, totalizando valores relativamente próximos aos de 2014, o que gera preocupação por parte do colegiado e dos docentes envolvidos no curso. Quanto ao número total de evadidos por ano de ingresso, percebemos que os valores não apresentaram grande variação, ficando entre 18 e 22 estudantes. No entanto, estes valores não são indicativos favoráveis à permanência no curso, pois, quando comparados ao número de ingressantes por ano $(44,30,31$ e 37$)$, percebemos que representam praticamente metade ou mais de $60 \%$ da turma.

Ao analisarmos os valores apresentados no Quadro 4, verificamos que o índice de evasão permaneceu com valores bastante próximos, sendo de 36,2\% em 2011; $38,2 \%$ em 2012; 38,9\% em 2013; e, 36,5\% em 2014. Por se tratarem de uma média percentual entre o índice de evasão de todas as instituições que oferecem cursos de formação de professores de Química do Brasil, estes valores indicam um alto índice de evasão.

O alto índice de evasão aqui identificado se assemelha aos resultados obtidos em outras pesquisas (MARTINHO et al., 2016; NUNES et al., 2014; VELOSO; 
ALMEIDA, 2002). Veloso e Almeida realizaram um estudo acerca da evasão em 14 cursos da Universidade Federal do Mato Grosso, e identificaram que no curso de Licenciatura em Química, o índice foi de aproximadamente $73 \%$. Nunes et al. (2014) estudaram a evasão dos estudantes no curso de licenciatura em Química do IFPI - Campus de Parnaíba nos anos de 2009 a 2014, cuja a média de evasão foi de aproximadamente 50\%. E, Martinho et al. (2016), ao investigarem as causas da evasão dos ingressantes no período de 2010 a 2011 do Curso de Licenciatura em Química do Instituto Federal de Educação, Ciência e Tecnologia do Campus Zé Doca - MA, identificaram um percentual de aproximadamente $48 \%$ de evadidos.

Por conseguinte, a partir das categorias de análise apresentadas anteriormente, construímos o Quadro 5, que indica o tipo de evasão registrado em documentos da universidade para os estudantes das turmas ingressantes nos anos de 2011 a 2014.

Quadro 5 - Tipos de evasão registrados nos relatórios da PROGRAD para os estudantes ingressantes nos anos de 2011 a 2014

\begin{tabular}{|c|c|c|c|c|c|c|c|}
\hline \multirow{2}{*}{ 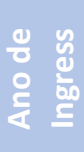 } & \multirow{2}{*}{$\begin{array}{l}\text { Trajetória } \\
\text { acadêmica }\end{array}$} & \multicolumn{5}{|c|}{ Tipos de Evasão } & \multirow{2}{*}{$\begin{array}{l}\text { Total de } \\
\text { Evadidos }\end{array}$} \\
\hline & & $\begin{array}{l}\text { Canc. de } \\
\text { Matrícula }\end{array}$ & Desist. & $\begin{array}{c}\text { Abandono } \\
\text { (Art. 43) }\end{array}$ & $\begin{array}{l}\text { Transf. } \\
\text { Interna }\end{array}$ & $\begin{array}{l}\text { Tranc. de } \\
\text { Matrícula }\end{array}$ & \\
\hline \multirow{6}{*}{ 곰 } & 2011 & 1 & - & - & - & - & 1 \\
\hline & 2012 & 1 & 5 & - & - & - & 6 \\
\hline & 2013 & 1 & 2 & 1 & - & - & 4 \\
\hline & 2014 & 1 & - & 3 & - & - & 4 \\
\hline & 2015 & - & - & 3 & - & 1 & 4 \\
\hline & 2016 & - & - & 3 & - & - & 3 \\
\hline \multirow{5}{*}{ స్ํำ } & 2012 & 2 & - & - & - & - & 2 \\
\hline & 2013 & 4 & 2 & 2 & - & - & 8 \\
\hline & 2014 & - & - & 1 & - & 1 & 2 \\
\hline & 2015 & 1 & 2 & 2 & - & - & 5 \\
\hline & 2016 & 1 & 1 & 1 & - & - & 3 \\
\hline \multirow{4}{*}{$\stackrel{m}{\stackrel{n}{0}}$} & 2013 & 2 & - & - & - & - & 2 \\
\hline & 2014 & 2 & - & 10 & - & - & 12 \\
\hline & 2015 & 2 & - & - & - & - & 2 \\
\hline & 2016 & - & 1 & 1 & - & - & 2 \\
\hline \multirow{3}{*}{ 总 } & 2014 & 6 & - & - & - & - & 6 \\
\hline & 2015 & 1 & 2 & 2 & - & 1 & 6 \\
\hline & 2016 & 1 & 2 & 2 & 2 & - & 7 \\
\hline \multicolumn{2}{|c|}{ Total dos evadidos } & 26 & 17 & 31 & 2 & 3 & 79 \\
\hline
\end{tabular}

Fonte: Autoria própria (2017).

Analisando os valores apresentados no Quadro 5 percebemos que a categoria que apresenta o maior número de estudantes evadidos é a que está relacionada 
ao Abandono (Art. 43) sendo mais acentuada na turma ingressante de 2013 (11 estudantes), seguida da turma ingressante de 2011 (10 estudantes). A categoria Cancelamento de Matrícula também apresentou um índice elevado de estudantes evadidos, sendo mais recorrente nas turmas ingressantes de 2012 (8 estudantes) e 2014 (8 estudantes). Na categoria Desistência há um total de 17 estudantes evadidos, sendo mais presente na turma de 2011 (7 estudantes), seguida pela turma ingressante de 2012 ( 5 estudantes). Houve Transferência Interna apenas na turma de 2014 (2 estudantes) e a categoria Trancamento de Matrícula foi identificada nas turmas de 2011, 2012 e 2014, sendo 1 estudante em cada ano, respectivamente.

Esses resultados indicam que não é possível estabelecermos um parâmetro para os tipos de evasão, visto que em cada turma os estudantes evadiram por distintos motivos, como registrado nos relatórios da universidade. No entanto, ao analisarmos a evolução total dos evadidos de 2011 a 2014, é perceptível que a evasão por Abandono de curso (Art. 43), Cancelamento de matrícula e Desistência são as que apresentaram o maior número de estudantes, enquanto que a evasão por transferência interna e trancamento de matrícula foram pouco expressivas diante da quantidade total de evadidos.

Outro aspecto interessante é que nas turmas de 2011 a 2013, o maior índice de evasão ocorreu no segundo ano do curso. Isso indica que o primeiro ano parece ser crucial aos estudantes quanto a escolha por se manter ou não no curso. Para Arruda et al. (2006) um motivo significativo para a evasão escolar é a falta de informações sobre o curso e também a profissão escolhida. Muitas vezes o aluno opta em fazer determinado curso, mas quando começa a estudar verifica que não condiz com a realidade, ou com aquilo que imaginava que a profissão the ofereceria.

Aqui refletimos que o curso pode não ter atingido as expectativas dos estudantes e que um dos motivos pode estar na grade curricular, uma vez que o primeiro ano é constituído principalmente por disciplinas de conhecimentos específicos e tem apenas uma disciplina direcionada para a licenciatura.

Para a turma de ingressantes em 2014, o maior índice de evasão ocorreu no terceiro ano. Essa turma em específico sofreu consequências da greve tanto no ano de ingresso quanto no terceiro ano do curso, sendo a turma com maior número de evadidos nos três primeiros anos do curso.

Uma pesquisa realizada por Cunha, Tunes e Silva (2001) aponta que a evasão tende a aumentar se a IES não proporcionar o envolvimento do estudante em atividades de pesquisa e extensão, uma vez que, estas permitem a união entre a teoria e a prática na aprendizagem. Não podemos deixar de levar também em consideração a estrutura curricular do curso, a qual deve incentivar os estudantes atendendo a suas necessidades formativas, de modo que construam um repertório de informações e habilidades composto pela pluralidade de conhecimentos teóricos e práticos, fundamentado em princípios de interdisciplinaridade, contextualização, democratização, pertinência e relevância social, ética e sensibilidade afetiva e estética (BRASIL, 2015).

Para além dos aspectos já mencionados, consideramos que os motivos que levam os estudantes a evadirem podem ser diversos como, a complexidade conferida às disciplinas específicas do curso, ao descaso dos gestores públicos 
brasileiros com os profissionais da Educação Básica, a falta de recursos financeiros para prosseguir nos estudos, entre outros.

No entanto, é preciso que fique claro que a diplomação ou evasão dos estudantes não pode ser interpretada apenas como valores numéricos, é fundamental ter-se clareza dos fatores e motivos que os levam a evadir e a forma como a organização curricular do curso tem influenciado para que ocorra a desistência, abandono, trancamento de matrícula, enfim, a interrupção dos estudos. Nesse contexto, ressaltamos a importância de identificar e analisar também os motivos que levam os estudantes a permanecerem no curso, objetivo futuro da nossa investigação.

\section{CONSIDERAÇÕES FINAIS}

Considerando o objetivo pretendido neste trabalho - apresentar algumas reflexões provenientes da análise dos dados referentes às turmas ingressantes nos anos de 2011 a 2014, sobre o ingresso e a evasão dos estudantes de um curso de licenciatura em Química de uma universidade pública do estado do Paraná. Comparando o número de ingressantes e de evadidos, bem como os tipos de evasão que constam em relatórios da PROGRAD - Pró-Reitoria de Graduação -, como resultados de nossa investigação temos que o processo de ingresso dos estudantes no curso referente aos anos de 2011 a 2014 foi predominantemente via ENEM, preenchendo mais de $60 \%$ das vagas. Apenas no ano de 2011 que a forma de ingresso predominante foi o Vestibular. Outro ponto a ressaltar é que das 40 vagas ofertadas por turma não houve vagas ociosas, somente no ano de 2011, o que evidencia a baixa procura dos estudantes pelo curso, como apontado na literatura da área.

No que diz respeito aos dados de evasão expressos no relatório analisado, observa-se que praticamente metade dos estudantes que ingressam na turma acaba evadindo. Outra observação oriunda dos dados é que apenas uma pequena porcentagem de estudantes (menos de $25 \%$ ) termina o curso no tempo mínimo previsto, de 4 anos.

Em relação às justificativas apresentadas no relatório para os estudantes evadidos, a que apresenta a maior incidência está relacionada ao Abandono (Art.43), considerado quando o estudante é reprovado em todas as atividades acadêmicas por nota e frequência durante 1 ano letivo. Em seguida, a categoria mais representativa é o Cancelamento de Matrícula, que se refere ao cancelamento do curso solicitado por escrito pelo estudante; esta categoria é responsável por $33 \%$ dos evadidos. A 3a categoria mais expressiva é o Desistente, sendo considerado desistente o estudante que não renova a matrícula dentro dos prazos previstos; esta categoria abarca cerca de $22 \%$ dos estudantes evadidos.

Outra informação originada dos dados fornecidos é que o maior índice de evasão, nas turmas analisadas, ocorreu no segundo ano do curso, dado este que pode suscitar alterações na grade curricular do 1 을.

Diante dos dados apresentados enfatizamos a necessidade de estudos como este que busca analisar a trajetória dos estudantes ao longo dos anos, os fatores que os levam a permanecer no curso, as dificuldades oriundas das disciplinas e os motivos que os levam a interromperem seus estudos. Portanto, destacamos a 
importância desse primeiro levantamento e ressaltamos a necessidade de aprofundarmos nossas investigações para além dos valores numéricos, aspecto este que será o nosso próximo passo de investigação. 


\title{
Characterizing elements of entrance and evasion in a Chemistry degree course in
}

\begin{abstract}
The objective of this article was to analyze the academic journey of the students of an undergraduate course in Chemistry from 2011 to 2014, since its entry until the end of 2016. The data analyzed consists of reports provided by the Dean of Graduation of a public university of the state of Paraná, referring to the students' admission from 2011 to 2014 and the trajectory of each of them until the end of 2016. It has been used the Content Analysis in order to analyze and to interpret the data. The discussions presented herein are the first results of a research project still in progress. The data indicate that students entering from 2012 to 2014 were predominantly via ENEM, once, in 2011 there was still no possibility of joining through this process; The total number of evaders per year of admission is equivalent to more than half of the class; (39\%), followed by the categories of Cancellation of Enrollment (33\%) and Withdrawal (22\%). It is clear that student graduation or avoidance cannot being interpreted as merely numerical values, it is essential to be clear about the factors and reasons that lead them to evade and how the curricular organization of the course influences withdrawal, abandonment, taking time off, in short, the interruption of studies is the future objective of our investigation.
\end{abstract}

KEYWORDS: Evasion. Higher education. Graduation. Chemistry. Teacher training. 


\section{AGRADECIMENTOS}

Agradecimentos à PROGRAD da Universidade Estadual de Londrina.

\section{NOTAS}

1 Neste trabalho consideramos como trajetória a situação do estudante no curso, ou seja, cursando, formado, formado ativo (colou grau em licenciatura e está cursando outra graduação na instituição) ou evadido.

20 PROUNI é um programa do Ministério da Educação, criado pela Lei no 11.096, de 13 de janeiro de 2005, que concede bolsas de estudo integrais e parciais de $50 \%$ em instituições privadas de educação superior, em cursos de graduação e sequenciais de formação específica, a estudantes brasileiros sem diploma de nível superior. Disponível em:

$<$ http://siteprouni.mec.gov.br/tire_suas_duvidas.php\#conhecendo >. Acesso em 23 abr. 2017.

3 De acordo com o Regimento Geral da UEL (UEL, 2016), o Art. 43 se refere ao cancelamento ou recusa da matrícula do estudante; no entanto, para melhor entendimento entre os funcionários da universidade, quando se refere ao "Art. 43 ", entende-se apenas abandono.

$4 \mathrm{O}$ Instituto Nacional de Estudos e Pesquisas Educacionais Anísio Teixeira (Inep) é uma autarquia federal vinculada ao Ministério da Educação (MEC), cuja missão é promover estudos, pesquisas e avaliações sobre o Sistema Educacional Brasileiro com o objetivo de subsidiar a formulação e implementação de políticas públicas na área educacional a partir de parâmetros de qualidade e equidade, bem como produzir informações claras e confiáveis aos gestores, pesquisadores, educadores e público em geral. Disponível em:

http://portal.inep.gov.br/web/guest/sobre-o-inep/. Acesso em 19 dez. 2016. 


\section{REFERÊNCIAS}

ANDERSON, E. C. Influência das forças na persistência do estudante e realização. San Francisco-London: Jossey-BessPublishers, 1987.

ARRUDA, S. M.; CARVALHO, M. A.; PASSOS, M. M.; SILVEIRA, F. L. Dados comparativos sobre a evasão em Física, Matemática, Química e Biologia da universidade estadual de Londrina: 1996 a 2004. Caderno Brasileiro de Ensino de Física, v. 23, n. 3, p. 418-438, 2006. Disponível em:

http://www.uel.br/prograd/gepe/materiais/evasao.pdf. Acesso em: 12 dez. 2016.

ARRUDA, S. M.; PASSOS, M. M. A relação com o saber na sala de aula.In: Colóquio Internacional "Educação e Contemporaneidade" Mesa-redonda Relação com o Saber e o Ensino de Ciências e Matemática, 9., 2015, Aracaju - SE. Anais... Aracaju - SE, 2015. Disponível em: http://educonse.com.br/ixcoloquio/arruda passos2.pdf. Acesso em: $22 \mathrm{dez}$. 2016.

BARDIN, L. Análise de conteúdo. São Paulo: Edições 70, 2011.

BORDAS. M. C. Diplomação, retenção e evasão nos cursos de graduação em instituições de ensino superior públicas. ANDIFES/ABRUEM/SESu/MEC. 1996. Disponível em: http://www.andifes.org.br/wpcontent/files flutter/Diplomacao Retencao Evasao Graduacao em IES Publica s-1996.pdf. Acesso em: 24 abr. 2017.

BRASIL. Resolução CNE/CP 2/2015, de 01 de julho de 2015. Define as Diretrizes Curriculares Nacionais para a formação inicial em nível superior (cursos de licenciatura, cursos de formação pedagógica para graduados e cursos de segunda licenciatura) e para a formação continuada. Diário Oficial da União, Brasília, 2 jul. 2015. Disponível em:

http://portal.mec.gov.br/index.php?option=com docman\&view=download\&alias $=17719$-res-cne-cp-002-03072015\&category slug=julho-2015pdf\&Itemid=30192. Acesso em: 20 nov. 2016.

CHEVALLARD, Y. La transposicióndidáctica: del saber sabio al saber enseñado. Buenos Aires: Aique Grupo Editor, 2005.

CUNHA, A. M.; TUNES, E.; SILVA, R. R. Evasão do curso de Química da Universidade de Brasília: a interpretação do aluno evadido. Química Nova, v. 24, n. 1, p. 262-280, 2001. Disponível em: http://www.scielo.br/pdf/qn/v24n2/4291.pdf. Acesso em: 13 de mar. 2017. 
FARIAS, S. A.; FRANCISCO JUNIOR, W. E. FERREIRA, L. H. Motivação na escolha de um curso universitário: a valorização do diploma de nível superior nos cursos de Licenciatura em Química. In: Encontro Nacional de Ensino de Química, 15., 2010, Brasília - DF. Anais... Brasília-DF, 2010. Disponível em:

http://www.sbq.org.br/eneq/xv/resumos/R0126-2.pdf. Acesso em: 22 dez. 2016.

FERNANDES, C. L.; SOARES NETO, J. G.; NASCIMENTO, P. H. L.; OLIVEIRA, M. J. O impacto da desvalorização da licenciatura na formação de professores na área de Química. In: Congresso Nacional de Educação, 3., 2016, Natal - RN. Anais... NatalRN, 2016. Disponível em:

http://www.editorarealize.com.br/revistas/conedu/trabalhos/TRABALHO EV056 MD1 SA4 ID10255 15082016185015.pdf. Acesso em: 20 nov. 2016.

GAIOSO, N. P. L. O fenômeno da evasão escolar na educação superior no Brasil. 2005. 75f. Dissertação (Mestrado em Educação). Universidade Católica de Brasília, 2005.

GATTI, B. A. Formação inicial de professores para a educação básica: pesquisas e políticas educacionais. Estudos em Avaliação Educacional, v. 25, n. 57, p. 24-54, 2014. Disponível em:

http://www.fcc.org.br/pesquisa/publicacoes/eae/arquivos/1899/1899.pdf.

Acesso em: 26 de jun. 2017.

INSTITUTO NACIONAL DE ESTUDOS E PESQUISAS EDUCACIONAIS ANÍSIO TEIXEIRA. Sinopse Estatística da Educação Superior 2015. Brasília: Inep, 2016. Disponível em: http://portal.inep.gov.br/web/guest/sinopses-estatisticas-daeducacao-superior. Acesso em: 19 dez. 2016.

INSTITUTO NACIONAL DE ESTUDOS E PESQUISAS EDUCACIONAIS ANÍSIO TEIXEIRA. Sinopse Estatística da Educação Superior 2014. Brasília: Inep, 2015. Disponível em: http://portal.inep.gov.br/web/guest/sinopses-estatisticas-daeducacao-superior. Acesso em: 19 dez. 2016.

INSTITUTO NACIONAL DE ESTUDOS E PESQUISAS EDUCACIONAIS ANÍSIO TEIXEIRA. Sinopse Estatística da Educação Superior 2013. Brasília: Inep, 2014. Disponível em: http://portal.inep.gov.br/web/guest/sinopses-estatisticas-daeducacao-superior. Acesso em: 19 dez. 2016.

INSTITUTO NACIONAL DE ESTUDOS E PESQUISAS EDUCACIONAIS ANÍSIO TEIXEIRA. Sinopse Estatística da Educação Superior 2012. Brasília: Inep, 2013. Disponível em: http://portal.inep.gov.br/web/guest/sinopses-estatisticas-daeducacao-superior. Acesso em: 19 dez. 2016. 
INSTITUTO NACIONAL DE ESTUDOS E PESQUISAS EDUCACIONAIS ANÍSIO TEIXEIRA. Sinopse Estatística da Educação Superior 2011. Brasília: Inep, 2012. Disponível em: http://portal.inep.gov.br/web/guest/sinopses-estatisticas-daeducacao-superior. Acesso em: 19 dez. 2016.

MALDANER, O. A. A formação inicial e continuada de professores de química: professores/pesquisadores. 4 ed. Ijuí: Unijuí, 2013.

MARTINHO, M; GOMES, V. R.; COSTA, E. M. M. P.; LIMA, M. L. S.; LAGO, W. J. S. Evasão nas turmas de licenciatura em química de ingressantes em 2010/2011 no IFMA - campus Zé Doca. In: Congresso Nacional de Educação - CONEDU, 3., 2016, Natal - RN. Anais... Natal-RN, 2016. Disponível em: http://www.editorarealize.com.br/revistas/conedu/trabalhos/TRABALHO EV056 MD1 SA3 ID10207 17082016104651.pdf. Acesso em: 25 ab. 2017

MEZOMO, J. C. Educação e qualidade total. 2 ed. Petrópolis: Vozes, 1999.

NUNES, M.S.; MELO, A.A.; ROCHA, E.V.; SOUZA, L.K.M. Evasão de alunos no curso de licenciatura em química do IFPI - campus de Parnaíba nos anos de 2009 a 2014. In: Congresso Brasileiro de Química -CBQ, 54. Natal-RN. Anais... Natal -RN. 2014. Disponível em: http://www.abq.org.br/cbq/2014/trabalhos/6/531017395.html. Acesso em: 25 ab. 2017

PAREDES, A. S. A evasão do terceiro grau em Curitiba. São Paulo: NUPES, 1994.

PATTO, M. H. S. A produção do fracasso escolar: histórias de submissão e rebeldia. Rio de Janeiro: T.A. Queiroz, 1996.

RAMOS, R. D. P. A Formação de Professores no Curso de Licenciatura em Química da Universidade Estadual de Goiás: a pesquisa-ação colaborativa como eixo orientador das práticas formativas. 2016. 212f. Tese (Doutorado em Ensino de Química). Universidade Federal de Goiás, 2016. Disponível em: http://repositorio.bc.ufg.br/tede/handle/tede/5585. Acesso em: 20 nov. 2016.

SÁ, C. S. S.; SANTOS, W. L. P. Licenciatura em Química: carência de professores, condições de trabalho e motivação pela carreira docente. In: Encontro Nacional de Pesquisa em Educação em Ciências, 8., 2011, Campinas - SP. Anais... Campinas-SP, 2011. Disponível em: http://www.nutes.ufrj.br/abrapec/viiienpec/resumos/R0544-1.pdf. Acesso em: 13 mar. 2017. 
Disponível em:

http://periodicos.uniso.br/index.php/avaliacao/article/view/1078/1074. Acesso em: 13 mar. 2017.

SGANZERLA, N. M. Z. Aspectos relevantes da estatística e a evasão de estudantes no curso de graduação em estatística da UFPR. 2001. 285f. Tese (Doutorado em Educação) Universidade Estadual Paulista, Marília, 2001.

SILVA FILHO, R. L. L.; MOTEJUNAS, P. R.; HIPÓLITO, O.; LOBO, M. B. C. M. A evasão escolar no ensino superior brasileiro. Cadernos de Pesquisa, v. 37, n. 132, p. 641659, 2007. Disponível em: http://www.scielo.br/pdf/cp/v37n132/a0737132.pdf. Acesso em: 13 mar. 2017.

UNIVERSIDADE ESTADUAL DE LONDRINA - UEL. Regimento Geral da UEL. Londrina, 2016. Disponível em:

http://www.uel.br/aai/pages/arquivos/Regimento Geral 201403 19.pdf. Acesso em: 13 mar. 2017.

VELOSO, T. C. M. A.; ALMEIDA, E. P.; Evasão nos cursos de graduação da universidade federal de Mato Grosso, campus universitário de Cuiabá - um processo de exclusão. Serie-Estudos - Periódico do Programa de Pós-Graduação em Educação da UCDB, 2002. Disponível em: http://www.serieestudos.ucdb.br/index.php/serie-estudos/article/view/564/453. Acesso em: 25 abr. 2017.

Recebido: 29 mai. 2017

Aprovado: 21 jul. 2017

DOI: 10.3895/actio.v2n1.6757

Como citar:

ARRIGO, V.; SOUZA, M. C. C. de; BROIETTI, F. C. D. Elementos caracterizadores de ingresso e evasão em

um curso de licenciatura em Química. ACTIO, Curitiba, v. 2, n. 1, p. 243-262, jan./jul. 2017. Disponível em:

$<$ https://periodicos.utfpr.edu.br/actio>. Acesso em: XXX.

Correspondência:

Viviane Arrigo

Rua São Paulo, Caixa Postal: 993, Bairro: Centro, CEP: 86840-000, Faxinal, PR, Brasil.

Direito autoral: Este artigo está licenciado sob os termos da Licença CreativeCommons-Atribuição 4.0

Internacional. 